\author{
K.K. Shulembayeva*, A.A. Tokubayeva \\ School of Biology and Biotechnology, al-Farabi Kazakh National University, Almaty, Kazakhstan \\ "E-mail: Kulziya.Shulembaeva@kaznu.kz
}

\title{
Genetic analysis of resistance to leaf rust in introgressive lines obtained by interspecific hybridization
}

\begin{abstract}
Leaf-rust highly resistant introgressive wheat lines have been studied genetically using effective $L r$ genes from Thatcher's isogenic lines and "Kazakhstanskaya 126" monosomic lines. Resistance genes $\operatorname{Lr} 9, \operatorname{Lr} 19, \operatorname{Lr} 9, \operatorname{Lr} 24$ and $L r 26$ in line L-344 were shown not to be allelic. $L r 9$ and $L r 26$, allelic genes conferring resistance to leaf rust have been identified in line L-345. The "leaf rust" resistance gene in the L-344 line is localized on a morphologically marked 5A chromosome, while the same gene in the L-345 line is located on 2B and 4B chromosomes.

Keywords: gene, recombination, genotype, leaf rust, wheat.
\end{abstract}

\section{Introduction}

Wild relatives of the wheat are an inexhaustible source of new and useful genes for the crop improvement. Set up collection of wheat lines resistant to different rust types is important step for improving genetic resources and related breeding processes. The success of hybridization in wheat breeding is determined by: 1) the creation of highly adaptive, productive and disease resistant wheat lines, 2) searching wild types with economically-valuable traits, 3) use of novel, unconventional techniques for recombination of foreign genes resulted in new genotypes.

To date, a number of standard methods have been offered in order to facilitate the gene transfer from species having no relationship to the bread wheat genomes. Some of these techniques are based on methods of chromosome engineering, which assume insertion of the chromosomal fragments carrying desired genes into the wheat chromosomes.

R. Riley, V. Chapman and R. Riley, C.Kempanna have noticed that only the homologues take part in conjugation in the presence of wheat $5 \mathrm{~B}$ chromosome. In the absence of this chromosome the process is accompanied by the formation of the multivalents. The mechanism controlling such abnormal formation of bivalents, takes place during the gemizygotic state, i.e. if a single $5 \mathrm{~B}$ chromosome is present. This method also allows introduction of desired genes into the wheat karyotype. Consequently, the long arm of the chromosome indicated above is in charge of the chromosomal bivalent conjugation in course of meiosis in the hexaploid wheat. Since the study of the rest of nullisomics does not demonstrate the effect on meiosis similar to that one in the presence of $5 \mathrm{~B}$ chromosome, it has been concluded that the gene that suppresses conjugation of the homologous chromosomes, has no copies in other chromosomes of $T$. aestivum $[1,2]$.

Tetraploid endemic species Triticum timopheevii Zhuk (genetic formula: $\mathrm{A}^{\mathrm{t}} \mathrm{A}^{\mathrm{t}} \mathrm{GG}$ ) is characterized by a unique gene pool controlling resistance to various wheat diseases. Generation and extensive use of soft wheat donors in breeding manipulations with effective resistance $\mathrm{Lr}$ genes, transferred from wild relatives, could significantly expand their genetic basis regarding one or the other economically valuable trait. However, despite few difficulties (hybrids sterility and cytological instability), literature contains sufficient information on transferring a number of genes conferring resistance to leaf rust, stem rust and powdery mildew from $T$. timopheevii to the soft wheat $[3,4]$.

Current research is focused on genetic analysis of resistance to leaf rust of introgression lines derived from a complex hybridization of soft wheat (T. aestivum, $2 \mathrm{n}=42$ ) "Kazakhstanskaya-3" 
line with $T$. timopheevi $(2 \mathrm{n}=28)$ and subsequent two-fold saturating breeding. Later, the 344 and 345 lines (L-344 and L-345) resistant to brown, yellow and stem rust, and also renowned for their good quality of grain, were picked out of hybrid offspring by repeated breeding.

L-344 and L-345 resistance to the leaf rust was revealed by Tatcher's testing of isogenic lines with effective $\operatorname{Lr} 9, \operatorname{Lr} 19, \operatorname{Lr} 23, \operatorname{Lr} 24, \operatorname{Lr} 26$ and $L r 29$ genes.

\section{Materials and methods}

Research objects: Kazakhstanskaya 3, and Bezostaya1 varieties, T. timopheevi species, L-344 and L-345 introgressive lines, monosomic lines of Kazakhstanskaya $126, \mathrm{~F}_{1}$, and $\mathrm{F}_{2}$ hybrids.

Methods of study: hybridologic and monosomic analysis [5]. The resistance of plants to the leaf rust was assessed by Mains and Jackson's scale [6]. Mathematical data processing was carried out using $\chi^{2}$ test [7].

\section{Results and their discussion}

Resistance of L-344 and L-345 lines has been tested in the natural conditions of severely infected fields of the Kazakh Institute of Agricultural Research and Cropping.

Genetic analysis of resistance to leaf rust of $F_{1}$ hybrid plants received from crossing the line L-344 and L-345 with effective "Tatcher" carriers of $\mathrm{Lr}$ genes has shown that all the plants were highly resistant to leaf rust. Dominating character of inheritance of "leaf rust" resistance in these lines has been depicted.

Results of the population analysis of $\mathrm{F}_{2}$ hybrids received from crossing of the L-344 and L-345 lines with effective Lr genes have indicated that all hybrids would split into resistant and susceptible plants thus reflecting digenic inheritance, with the exception of hybrid population for isogenic Lr19 line (Table 1).

Splitting in hybrid $\mathrm{F}_{2}$ progeny allows to conclude that in this case highly effective resistance genes $\operatorname{Lr}$ 9, $\operatorname{Lr} 19, \operatorname{Lr} 23, \operatorname{Lr} 24, \operatorname{Lr} 26$ and $\operatorname{Lr} 29$ are not allelic in L-344 line. It shows the presence of one or few novel genes controlling the leaf rust in this line. Newly-identified resistance gene in L-344 has been designated as LrG.

Opposite data have been obtained with L-345 line. Here there has been no splitting observed in $\mathrm{F}_{2}$ population with tester $L r 9$ and $L r 26$ lines. This might indicate that "leaf rust" resistance genes in this case are allelic.

Actual values of splitting between resistant and susceptible wheat lines obtained by testing with other Lr tester genes have corresponded to the complementary and epistatic gene interactions with the exception of a $L r 23 \times$ L-345 combination. Thus, $\chi^{2}$ distribution has been in consent with monogenic inheritance $\left(\chi^{2}=2.13\right)$ of the trait considered.

Mandatory condition for the identification of disease resistance genes in the donors is their chromosomal localization. The level of resistance to the race 56 of leaf rust in L-344 and L-345 lines has showed the score "0". "Kazakhstanskaya 126" line revealed a strong susceptibility to this type of the rust (the degree of affect - score " 4 ").

Analysis of $F_{1}$ hybrids in disomic and monosomic crossing combinations has determined a dominant inheritance of the leaf rust resistance trait in the introgressive lines.

Analysis of $F_{2}$ hybrids resulting from mono Kazakhstanskaya 126 lines crossings with L-344 and L-345

Study of $\mathrm{F}_{2}$ progeny from euploid combination of hybrids by crossings of cv. Kazakhstanskaya 126 with L-344 and L-345 introgressive lines has shown that the ratio of resistant (R) and susceptible (S) phenotypes would correspond to monogenic type of inheritance, $\chi^{2}=0.19$ (Table 1).

The data on chromosomal genes localization is depicted in brief, only for principal chromosomes.

The deviation from the expected 3:1 ration has been observed in crossing combinations of L-344 with monosomic lines in respect of $5 \mathrm{~A}, 6 \mathrm{~B}$ and $2 \mathrm{~B}$ chromosomes. The splittings in 5A line (179 resistant plants to 14 susceptible plants) have demonstrated considerable deviations in chi-square value $\left(\chi^{2}=32.58\right)$ from that one theoretically expected (3:1).

So, a $5 \mathrm{~A}$ chromosome of L-344 is confirmed to be critical for the resistance to leaf rust. Hybrids referred to chromosomes $1 \mathrm{~B}\left(\chi^{2}=4.67\right)$ or $6 \mathrm{~B}$ $\left(\chi^{2}=4.36\right)$, also have shown authentic deviation, if compared with control and other monosomic hybrids (Table 1). Apparently, these chromosomes carry the gene - modifiers which may enhance plant resistance. Data for other 17 combinations of monosomic hybrids has evidenced in favour of monogenic type of inheritance of a "leaf rust" resistance trait in the studied line. 
Table 1 - Principal chromosomes in charge of leaf rust resistance in $\mathrm{F}_{2}$ hybrids based on L-344 and L-345 in the phase of flag leaf

\begin{tabular}{|c|c|c|c|}
\hline \multirow[t]{2}{*}{ Chromosome } & \multicolumn{2}{|c|}{ Phenotypic ratio } & \multirow[t]{2}{*}{$\chi^{2}$ value at $3: 1$ ratio } \\
\hline & $\mathrm{R}$ & $\mathrm{S}$ & \\
\hline Kaz.126 x L-344, $\mathrm{F}_{2}$ & 201 & 64 & 0.19 \\
\hline $5 \mathrm{~A}$ & 179 & 14 & $32.58 * * *$ \\
\hline $1 \mathrm{~B}$ & 177 & 12 & $4.67 *$ \\
\hline $6 \mathrm{~B}$ & 122 & 25 & $4.36^{*}$ \\
\hline Chromosome & \multicolumn{2}{|c|}{ Phenotypic ratio } & $\chi^{2}$ value at $3: 1$ ratio \\
\hline Kaz.126 x L-345, F 2 & 185 & 47 & 0.34 \\
\hline $2 \mathrm{~B}$ & 152 & 8 & $19.85 * * *$ \\
\hline $4 \mathrm{~B}$ & 138 & 54 & $11.08 * * *$ \\
\hline
\end{tabular}

Strong deviation from the control hybrid was observed on chromosomes $2 \mathrm{~B}\left(\chi^{2}=19.85\right)$ and $4 \mathrm{~B}$ $\left(\chi^{2}=11.08\right)$ in crossing combinations of 21 monosomic lines with L-345.

Splitting analysis of the control crosses in $\mathrm{F}_{2}$ has lead to statistical hypothesis of digenic inheritance: the ratio has appeared to be closer to 13:3 (Table 1).

Monosomic analysis of all chromosomes belonging to $F_{2}$ hybrids, except $2 \mathrm{~B}$ and $4 \mathrm{~B}$ chromosomes, has shown theoretically expected splitting similar to the control.

\section{Conclusion}

The study on standard population of $F_{2}$ hybrids obtained from the crossing cv. Kazakhstanskaya $\mathrm{x}$ L-344 has shown that resistance of the introgressive line to leaf rust is inherited monogenically $\left(\chi^{2}=0.19\right)$.

Substantial deviation from anticipated 3:1 ration has been observed in combinations from L344 crossings by chromosome $5 \mathrm{~A}$ with monosomic lines $\left(\chi^{2}=32.58\right)$ comparing to $1 \mathrm{~B}\left(\chi^{2}=4.67\right)$ and $6 \mathrm{~B}$ chromosomes $\left(\chi^{2}=4.36\right)$.

The data obtained allows considering chromosome $5 \mathrm{~A}$ in L-344 to be critical for the determination of leaf rust reasistance. Chromosomes $1 \mathrm{~B}$ and $6 \mathrm{~B}$ carry modificator genes strengthening the resistance of principal gene allocated in $5 \mathrm{~A}$ chromosome.

$\chi^{2}$ value in standard combinations from the crossing of cv. Kazakhstanskaya 126 with L-345 is equal 0.34 .

Strong deviation from this standard value indicated for chromosome $2 \mathrm{~B}\left(\chi^{2}=19.85\right)$ shows that this chromosome is critical for leaf rust resistance in L-345, whereas insignificant deviation revealed for chromosome $4 \mathrm{~B}\left(\chi^{2}=11.08\right)$ may be associated with the impact of the modificator gene.

Leaf rust resistance genes localized into introgressive lines L-344 and L-345 are believed to extend the gene catalogue of soft wheat and be applied in wheat breeding for immunity.

\section{References}

1. Riley R., Chapman V. Genetic control of the cytologicalli diploid behaviour of hexaploid wheat // Nature. - 1958. - Vol. 182. - P. 713-715.

2. Riley R., Kempanna C. The homoelogous nature of the nonhomoelogues meiotic pairing in Triticum aestivum deficient for chromosome $\mathrm{V}$ (5B) // Heredity. - 1963. - Vol. 18. - P. 287-306.

3. Leonova, I.N., Laikova, L.I., Popova, O.M. Detection of quantitative trait loci for leaf rust resistance in wheat - T. timopheevii/T. tauschii introgression lines // Euphytica. - 2007. - Vol. 155. P. 79-86.

4. Guedira, G.L., Singh, S., and Fritz, A.K. Performance and Mapping of Leaf Rust Resistance Transferred to Wheat from Triticum timopheevii subsp. Armeniacu // Phytopathology. - 2003. Vol. 93. - P. 784-789.

5. Sears E.R. History of Chinese Spring aneuploids // Proseed. 7-th Intern. Wheat Genet. Symp. - Cambridge, 1988. - Vol. 1. - P. 3-6.

6. Mains E.B., Jackson H.S. Physiologic specialization leaf rust of wheat $P$. triticina Erikss // Phytopathology. - 1926. - Vol. 16. - P. 89-120.

7. Serebrovski A.S. Genetic analysis. Sience, 1970. $-346 \mathrm{p}$. 